\title{
Fat Utilization During High-Intensity Exercise: When Does It End?
}

\author{
Ratko Peric ${ }^{1 *}$, Marco Meucci ${ }^{2}$ and Zoran Nikolovski ${ }^{3}$
}

\begin{abstract}
Background: This study examined substrate oxidation at high-intensity exercise and aimed to determine when fat oxidation ends $\left(F A T_{\min }\right)$. We hypothesized the existence of a connection between the anaerobic threshold (AnT) and FAT $T_{\text {min }}$ point.

Methods: Breath-by-breath data obtained from indirect calorimetry during a graded treadmill test were used to measure substrate oxidation and maximal oxygen uptake $\left(\mathrm{VO}_{2 \max }\right)$ on 47 males (30 athletes (ATL) and 17 non-athletes (NATL)). Pearson correlation coefficient $(r)$ and effect size $\left(R^{2}\right)$ were used to test correlations between $\mathrm{VO}_{2}$ at AnT and at FAT min.

Results: Maximal oxygen uptake $\left(\mathrm{VO}_{2 \max }\right)$ was $56.17 \pm 4.95$ and $46.04 \pm 3.25 \mathrm{ml} \mathrm{kg}^{-1} \mathrm{~min}^{-1}$ in ATL and NATL, respectively. In ATL, AnT was observed at $87.57 \pm 1.30 \%$ of $\mathrm{VO}_{2 \max }$ and $\mathrm{FAT}_{\min }$ was observed at $87.60 \pm 1.60 \%$ of $\mathrm{VO}_{2 \max }$. In NATL, AnT and $\mathrm{FAT}_{\min }$ were at $84.64 \pm 1.10 \%$ of $\mathrm{VO}_{2 \max }$ and $85.25 \pm 1.10 \%$ of $\mathrm{VO}_{2 \text { max }}$, respectively. Our data show large correlations between $\mathrm{VO}_{2}$ at AnT and $\mathrm{VO}_{2}$ at FAT $\min$ for ATL $(r=0.99, p<0.01,95 \% \mathrm{Cl} 0.99$ to 1.00$)$ and NATL $(r=0.97, p<0.01,95 \%$ Cl 0.91 to 0.98). The effect size of correlations for ATL and NATL were 0.98 and 0.94, respectively.

Conclusions: Our results show high correlation between AnT and FAT $T_{\min }$ in both ATL and NATL with equal substrate oxidation rates at AnT.

Keywords: Fat, Oxidation, High intensity, Anaerobic threshold, Running

Abbreviations: AerT, Aerobic threshold; AMP, Adenosine monophosphate; AnT, Anaerobic threshold; ATL, Athletes; CHO, Carbohydrates; FAT max, Maximal point of fat oxidation; FAT max, Point at which the fat oxidation ends; FFA, Free fatty acids; GXT, Graded exercise testing; HSL, Hormone sensitive lipase; NATL, Non-athletes; Pi, Inorganic phosphate; $\mathrm{RQ}$, Respiratory quotient; $\mathrm{SD}$, Standard deviation; $\mathrm{VCO}_{2}$, Carbon dioxide production; $\mathrm{VO}_{2}$, Oxygen consumption;

VO2max, Maximal oxygen uptake; $\mathrm{VT}_{2}$, Second ventilatory threshold
\end{abstract}

\section{Key Points}

- A high correlation between $\mathrm{FAT}_{\min }$ and anaerobic threshold (AnT) exists in both athletes and recreationally active males.

- $\mathrm{CHO}$ and fat utilization at AnT are equal in both groups.

- At intensities above AnT, no presence of lipids in energy expenditure was observed.

\footnotetext{
* Correspondence: ratkoperic@yahoo.com

${ }^{1}$ Institute for Sport and Occupational Medicine Banja Luka, Zdrave Korde 4, 78000 Banja Luka, Bosnia and Herzegovina

Full list of author information is available at the end of the article
}

\section{Background}

It is well documented that carbohydrates $(\mathrm{CHO})$ and lipids are simultaneously oxidized during energy production. Although proteins are also involved in this process, their contribution to energy expenditure is minimal [17]. At the onset of exercise, there is an increase of glycolysis, which drops after several minutes if low or moderate intensity is maintained. During that time, there is an increase in fat oxidation in the muscle due to stimulation of lipolysis in adipose tissue, augmented muscle blood flow, possibly enhanced translocation of FAT/CD36 protein into the cell membrane, and the possibility of stimulated lipolysis in the muscles themselves through increased levels of hormone-sensitive lipase (HSL) [8]. Intensity of the exercise where there is maximal utilization of lipids as a fuel is referred to as $\mathrm{FAT}_{\max }$, which is correlated with 
aerobic threshold (AerT) $[3,5,9]$. In contrast to $\mathrm{CHO}$ oxidation, which increases together with the work rate, absolute fat oxidation rate declines at high-intensity exercises. Achten et al. [1] introduced the point where fat utilization becomes negligible $\left(\mathrm{FAT}_{\mathrm{min}}\right)$.

During prolonged activities at high-intensity exercises, the main energy source is $\mathrm{CHO}$ derived from the muscle and liver glycogen [26]. However, since the body can only store a limited amounts of this metabolic substrate (up to $600 \mathrm{~g}$ ), prolonged high-intensity physical activity above $\mathrm{FAT}_{\text {min }}$ could lead to depletion of glycogen stores, therefore making $\mathrm{FAT}_{\min }$ an important parameter to consider when exercising at high-intensity for long periods of time.

Few studies exist which were performed systemically and accurately with the aim of determining the intensity at which FAT $_{\text {min }}$ is reached. There are divergent study findings with previous research since some have shown negligible fat oxidation in cyclists and runners at intensities of approximately 80 to $95 \%$ of maximal oxygen uptake $\left(\mathrm{VO}_{2 \max }\right)[1-3,27]$. Yet, others report that fat oxidation was not negligible in cyclist and runners while exercising at the 86 and $95 \%$ of $\mathrm{VO}_{2 \max }[13,28]$. The wide range of intensities reported leads to inconsistency of data obtained and may be a consequence of differences between subject fitness levels and a lack of consistency of testing methodologies.

The mechanism behind fat utilization at high intensities has not been fully elucidated and the topic warrants further discussion. Horowitz and Klein [14] support the hypothesis that reduction of fat oxidation during highintensity exercise is caused by increased trapping of fatty acids within adipose tissue due to a decrease in blood flow and insufficient removal by the bloodstream. Another factor which can limit fat mobilization during high-intensity exercise is the lactate accumulated in the blood. Lactate promotes re-esterification of free fatty acids (FFA) produced during lipolysis limiting the entry of lipids into the bloodstream [19]. Dyck et al. [9] reported when increased fat is available in the plasma at high-intensity exercises (above $80 \%$ of $\mathrm{VO}_{2 \max }$ ), a reduction of glycolysis is observed and the breakdown of muscle glycogen decreases. Also, it has been shown that allosteric regulators (inorganic phosphate (Pi) and adenosine monophosphate (AMP)) play a major role in the regulation of glycogenolysis [17]. Van Loon et al. [29] reported low fat utilization during highintensity exercises hypothesizing that carnitine acts as a sink for acetyl group storage during continuous accumulation of muscle acetyl carnitine when oxygen deficit occurs.

The second ventilatory threshold $\left(\mathrm{VT}_{2}\right)$ or $\mathrm{AnT}$ is often considered a point of a transition from aerobic to anaerobic metabolism and a well-established marker of an individual's endurance capacity [12]. It varies from person to person and sport to sport. Due to the high individuality of each parameter, we hypothesize that $\mathrm{FAT}_{\text {min }}$ could correlate highly with AnT making it a valid indicator of substrate utilization and the end point of fat oxidation.

Therefore, the primary aim of this study was to assess the substrate oxidation at high-intensity physical activity and to determine the point at which FAT $_{\text {min }}$ occurs in athletes and non-athletes during a continuous incremental treadmill test. Furthermore, we aimed to explore an existence of relationships between $\mathrm{FAT}_{\min }$ and AnT.

\section{Methods \\ Participants}

Forty-seven healthy, non-smoking males (30 athletes (ATL) and 17 non-athletes (NATL)) participated in this study. ATL (basketball, football, and handball) competed at national or international levels and undertook $\geq 13 \mathrm{~h}$ of training per week over the last 8 years. NATL (recreational football) performed $\leq 2 \mathrm{~h}$ of physical activity per week for the last 6 months. Subjects were recruited through a voluntary, open-access, online poll. Prior to testing, all subjects completed a questionnaire regarding their exercise and health histories. Informed consent was obtained from all individual participants for whom identifying information is included in this article. This research was conducted according to the policies and a guideline provided by the Declaration of Helsinki and was approved by the Institutional ethics committee. Anthropometric values for both groups are presented in Table 1 . The body mass and height were assessed as they reported to the laboratory for the first time using a Seca 763 digital medical scale and stadiometer (SECA, Hamburg, Germany). Subjects were asked to abstain from any laborious physical activity $24 \mathrm{~h}$ prior to the testing and instructed to have their last meal $2 \mathrm{~h}$ before the testing session. Also, they were asked to refrain from consuming caffeine and nutritional supplements on the testing day. Pre-test meals were not standardized. Testing was performed between 09:00 and 12:00 $\mathrm{h}$ in the winter period. The laboratory where the study was performed was located $270 \mathrm{~m}$ above sea level, and standard conditions were maintained $\left(21^{\circ} \mathrm{C}\right.$ and $43 \%$ humidity).

\section{Exercise Protocols}

All subjects performed a graded exercise testing (GXT) on a T170D motorized treadmill (COSMED, Rome, Italy) until volitional exhaustion to measure gas concentration and to

Table 1 Anthropometric values of the subjects

\begin{tabular}{lll}
\hline & Athletes $(n=30)$ & Non-athletes $(n=17)$ \\
\hline Age (year) & $25.3 \pm 3.2$ & $26.8 \pm 3.1$ \\
Height $(\mathrm{cm})$ & $197 \pm 8.6$ & $176.5 \pm 6.5$ \\
Body mass $(\mathrm{kg})$ & $99 \pm 6.3$ & $85.6 \pm 6.3$ \\
\hline
\end{tabular}

Values are expressed as means \pm SD

$n$ number of subjects 
calculate the oxidation rate. All subjects were experienced in treadmill exercise testing. Oxygen consumption $\left(\mathrm{VO}_{2}\right)$ and carbon dioxide production $\left(\mathrm{VCO}_{2}\right)$ were assessed during exercise using a breathe-by-breath Quark PFT Ergo (COSMED , Rome, Italy) system. Prior to each test session, a two-point gas calibration for oxygen and carbon dioxide $\left(\mathrm{O}_{2} \mathrm{16.10}\right.$ and $20.93 \% ; \mathrm{CO}_{2} 0.00$ and $5.20 \%$, respectively) and a turbine flow meter calibration (3-L syringe) were performed according to the manufacturers' recommendation. Fluctuations of breath-by-breath data were minimized using a six-breath smoothing and consequent 30-s averaging. An experienced exercise physiologist determined AerT and AnT manually, using the methods described by Meyer et al. [21]. $\mathrm{VO}_{2 \max }$ was determined using the following criteria: a respiratory quotient $(\mathrm{RQ}) \geq 1.15$ or a plateau of $\mathrm{VO}_{2}$ in spite of a load increase [15]. The GXT protocol used consisted of three stages: rest, exercise, and recovery. The resting stage of 2 min standing was performed to obtain baseline values. The exercise stage started at $6 \mathrm{~km} \mathrm{~h}^{-1}$ speed and constant $1 \%$ incline, followed by an increase in speed of $1 \mathrm{~km} \mathrm{~h}^{-1}$ every $2 \mathrm{~min}$ until volitional exhaustion. A 3-min active recovery was performed immediately after stopping and required the subjects to run for a further $3 \mathrm{~min}$ at the starting speed in order to observe physiological recovery of the subjects. To test the reliability of the proto$\mathrm{col}$, a repeat test was performed on ten randomly selected subjects under identical laboratory conditions and daytime to avoid circadian variance. $\mathrm{VO}_{2 \max }$ data obtained were compared with the initial test.

\section{Metabolic Calculations}

Substrate oxidation was estimated continuously during GXT by using modified stoichiometric equation from Elia and Livesey [10], which assumed negligible contribution of protein oxidation.

- $\mathrm{RQ}=\mathrm{VCO}_{2} / \mathrm{VO}_{2}$ if calculated $\mathrm{RQ}<0.7$ than $\mathrm{RQ}=0.7$ or if calculated RQ $>1.0$ than $R Q=1.0$.

- $\mathrm{CHO} \%=(5.045 \times \mathrm{RQ}-3.582) /(0.36 \times \mathrm{RQ}+1.103)$

if $\mathrm{CHO} \%<0$ than $\mathrm{CHO} \%=0$ or if $\mathrm{CHO} \%>1$ than $\mathrm{CHO} \%=1.0$

- FAT $\%=1.0-\mathrm{CHO} \%$

$\mathrm{VO}_{2 \max }$ was expressed as maximum amount of oxygen in milliliters, used per kilogram of body weight in $1 \mathrm{~min}$ $\left(\mathrm{ml} \mathrm{kg}^{-1} \mathrm{~min}^{-1}\right)$. Fat and $\mathrm{CHO}$ utilization was expressed in grams per minute $\left(\mathrm{g} \mathrm{min}^{-1}\right)$ or as percentage of the total energy production. The test results for each individual were used to create a fat oxidation curve that was in turn used to determine $\mathrm{FAT}_{\text {min }}$.

\section{Statistical Analysis}

Data were analyzed and presented as mean \pm standard deviation $(\mathrm{SD}), 95 \%$ confidence interval $(\mathrm{CI})$, and lowest to highest values using MedCalc 12 (MEDCALC, Ostend, Belgium) statistical software. Normal distribution of all measured variables was assessed using the Shapiro-Wilk test with normal distribution accepted for all variables. A Student $t$ test was used to test-retest reliability of $\mathrm{VO}_{2 \max }$ protocol with no statistical differences observed $(p=0.76)$. To assess differences in measured parameters between ATL and NATL, we used Mann-Whitney $U$ test. A Pearson product-moment correlation coefficient $(r)$ was used to assess the linear relationship between $\mathrm{VO}_{2}$ at $\mathrm{AnT}$ and $\mathrm{VO}_{2}$ at $\mathrm{FAT}_{\text {min }}$. Coefficient of determination $\left(R^{2}\right)$ was used to detect the effect size and strength of relationships. Alpha intervals for all hypothesis testing were set at $p \leq$ 0.05 as the level of significance for statistical tests unless stated otherwise.

\section{Results}

The subjects' metabolic values are presented in Table 2. As expected, higher $\mathrm{VO}_{2 \max }$ results were found in ATL $(95 \%$ CI 54.32 to 58.05 ) compared to NATL ( $95 \%$ CI 44.37 to 47.71) $(U=0.00, p<0.01)$. AerT was reached at a $37.01 \pm$ $5.33 \mathrm{ml} \mathrm{kg}^{-1} \mathrm{~min}^{-1} \mathrm{VO}_{2}$ (95\% CI 34.02 to 39.56) in ATL and at a $23.59 \pm 4.51 \mathrm{ml} \mathrm{kg}^{-1} \mathrm{~min}^{-1} \mathrm{VO}_{2}$ (95\% CI 21.49 to 25.33) $(U=28.00, p<0.01)$ in NATL. Fat utilization increased with exercise intensity until the AerT was reached, followed by a decrease of total fat oxidation and an increase of $\mathrm{CHO}$ utilization (Fig. 1).

AnT was reached at a $49.19 \pm 6.52 \mathrm{ml} \mathrm{kg}{ }^{-1} \min ^{-1} \mathrm{VO}_{2}$ (95\% CI 46.76 to 51.63) in ATL and at a $38.97 \pm$ $3.26 \mathrm{ml} \mathrm{kg}^{-1} \mathrm{~min}^{-1} \mathrm{VO}_{2}(95 \%$ CI 37.29 to 40.65$)$ in NATL $(U=27.00, p<0.01)$.

FAT $_{\text {min }}$ was obtained at $49.22 \pm 6.53 \mathrm{ml} \mathrm{kg}^{-1} \mathrm{~min}^{-1}$ of $\mathrm{VO}_{2}$ (95\% CI 46.78 to 51.66$)$ or at $87.60 \pm 1.60 \%$ of $\mathrm{VO}_{2 \max }$ for ATL and $39.25 \pm 3.44 \mathrm{ml} \mathrm{kg}{ }^{-1} \mathrm{~min}^{-1}$ of $\mathrm{VO}_{2}$ (95\% CI 37.48 to 41.02 ) or at $85.25 \pm 1.10 \%$ of $\mathrm{VO}_{2 \max }$ for NATL $(U=29.00, p<0.01)$.

Pearson correlations between $\mathrm{VO}_{2}$ at AnT and at $\mathrm{FAT}_{\text {min }}$ in ATL (Fig. 2b) and NATL (Fig. 2a) was high $(r=0.99, p<$ $0.01,95 \%$ CI 0.99 to 1.00 and $r=0.97, p<0.01,95 \%$ CI 0.91 to 0.98$)$, respectively. Effect size for ATL was $R^{2}=0.98$ explaining for $98.01 \%$ of variance. NATL had $R^{2}=0.94$ effect size explaining $94.09 \%$ of variance.

Fat oxidation at AnT in ATL and NATL was $0.00 \pm$ $0.00 \mathrm{~g} \mathrm{~min}^{-1}$ (95\% CI -0.00 to 0.00 ) and $0.02 \pm 0.02 \mathrm{~g} \mathrm{~min}^{-1}$ (95\% CI 0.00 to 0.03$)(U=168.00, p<0.01)$, respectively.

Table 2 Subjects metabolic data

\begin{tabular}{lll}
\hline & Athletes $(n=30)$ & Non-athletes $(n=17)$ \\
\hline $\mathrm{VO}_{2 \max }\left(\mathrm{ml} \mathrm{kg}^{-1} \mathrm{~min}^{-1}\right)$ & $56.17 \pm 4.95$ & $46.04 \pm 3.25$ \\
AerT $\left(\% \mathrm{VO}_{2 \text { max }}\right)$ & $65.89 \pm 1.80$ & $51.25 \pm 2.10$ \\
AnT $\left(\% \mathrm{VO}_{2 \text { max }}\right)$ & $87.57 \pm 1.30$ & $84.64 \pm 1.10$ \\
\hline
\end{tabular}

Values are expressed as means \pm SD

$n$ number of subjects, AerT aerobic threshold, $A n T$ anaerobic threshold, $V_{2 \max }$ maximal oxygen uptake 


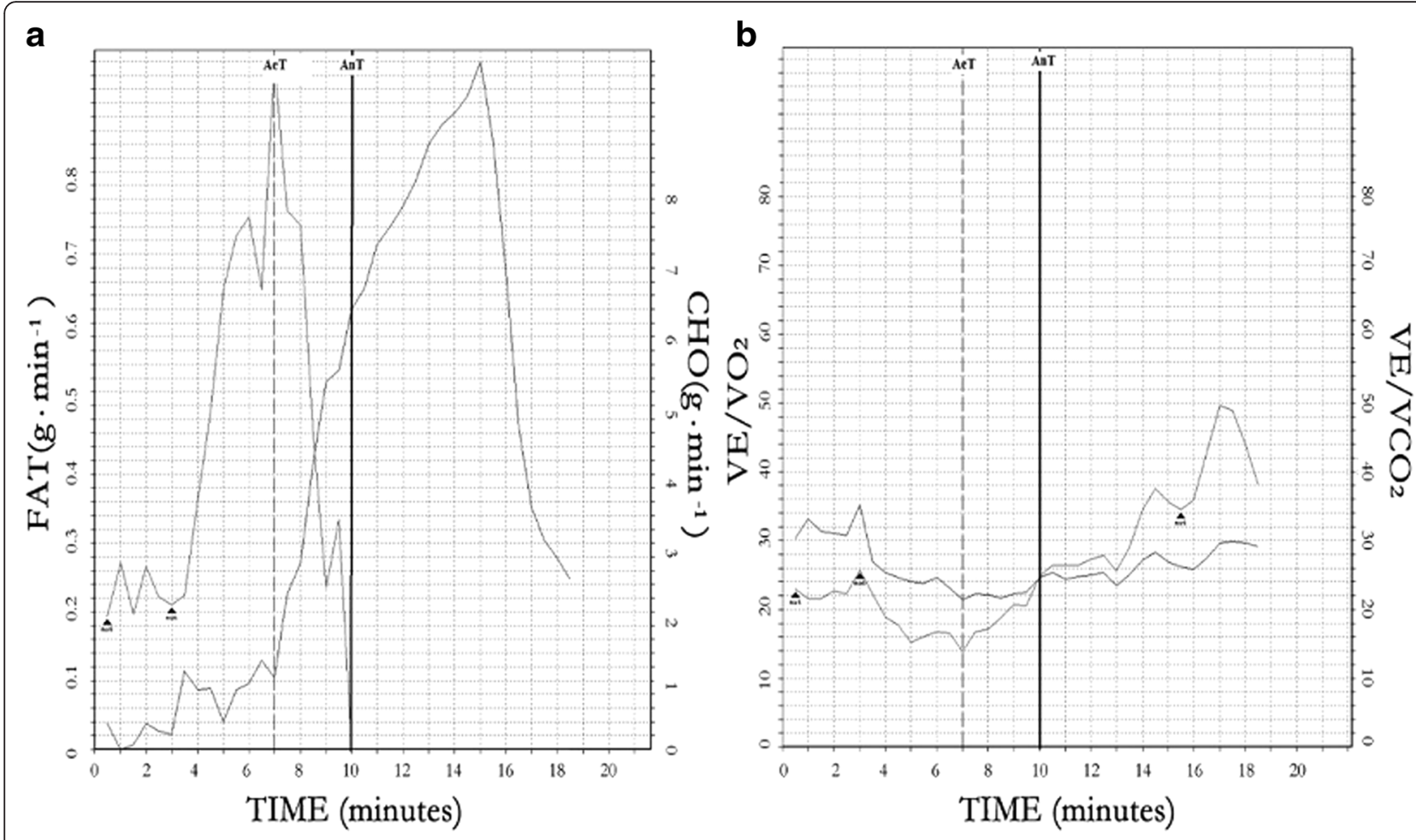

Fig. 1 Graphic representation of correlation between AerT and FAT max and AnT and FAT min. a Fat and CHO utilization $\left(\mathrm{g} \mathrm{min}^{-1}\right.$ ) at AerT and AnT in tested subjects (PFT Suite Software, COSMED, Rome, Italy). b Threshold detection method by $\mathrm{EqO}_{2}$ and EqCO $\mathrm{CO}_{2}$ principles [21]

$\mathrm{CHO}$ oxidation at AnT in ATL averaged $4.47 \pm$ $1.24 \mathrm{~g} \mathrm{~min}^{-1}$ (95\% CI 4.01 to 4.93 ) and provided $97.91 \pm$ $1.02 \%$ (95 \% CI 97.52 to 98.29 ) of the total energy expenditure. The lowest value was $94.50 \%$ and the highest $99.20 \%$. CHO utilization in NATL at AnT was equal to $4.17 \pm 0.95 \mathrm{~g} \mathrm{~min}^{-1}$ (95\% CI 3.68 to 4.66 ) with average contribution to total energy production of $96.99 \pm 2.21 \%$ (95\% CI 95.82 to 98.15 ). The lowest to highest value was 90.00 to $98.85 \%$. Mann-Whitney $U$ test revealed no difference in $\mathrm{CHO}$ oxidation between ATL and NATL at AnT, expressed in $\mathrm{g} \mathrm{min}^{-1}(U=207.50, p<0.29)$ or in percent of total energy contribution $(U=194.00, p<0.18)$.

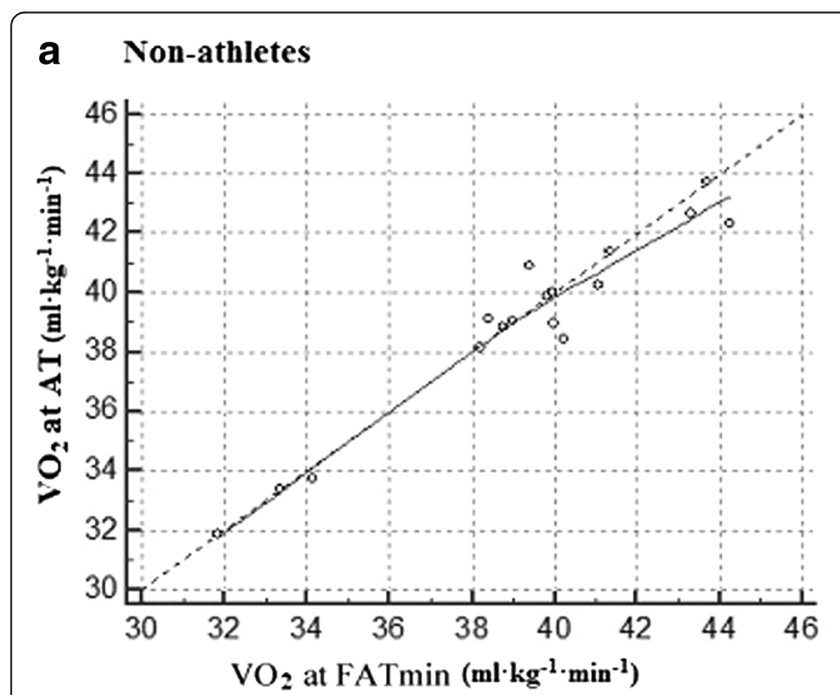

\section{b Athletes}

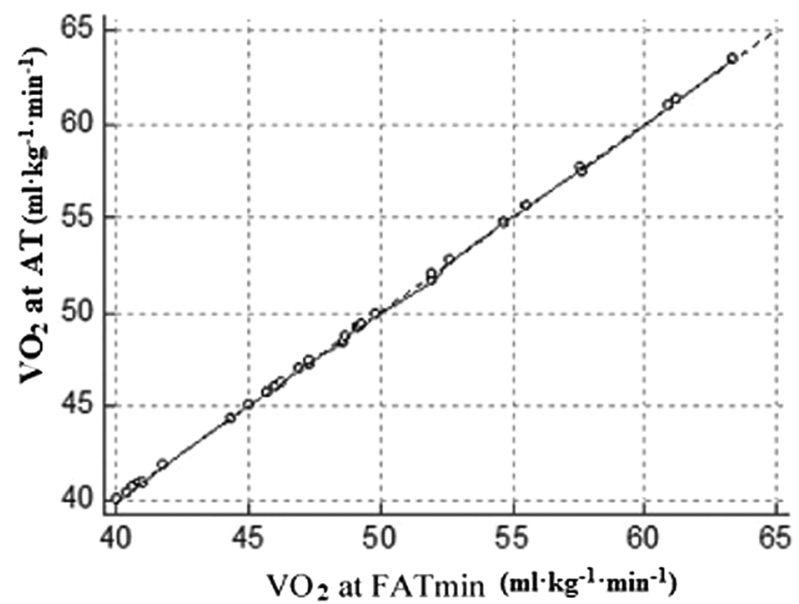

Fig. 2 Pearson correlation between $\mathrm{VO}_{2}\left(\mathrm{ml} \mathrm{kg}^{-1} \mathrm{~min}^{-1}\right)$ at AnT and at FAT $\min$ for NATL $(r=0.97, p \leq 0.01,95 \% \mathrm{Cl} 0.91$ to 0.98) (a) and ATL (r=0.99, $p \leq 0.01,95 \% \mathrm{Cl} 0.99$ to 1.00$)$ (b) with line of equality 


\section{Discussion}

The purpose of this study was to assess substrate oxidation during a GXT to exhaustion while determining the point at which FAT $_{\text {min }}$ occurs in ATL and NATL. Our secondary aim was to determine if there was a correlation between $\mathrm{VO}_{2}$ at AnT and at the $\mathrm{FAT}_{\text {min }}$. Our results showed that FAT $_{\text {min }}$ was obtained at $87.60 \pm 1.60 \%$ of $\mathrm{VO}_{2 \max }$ in ATL and at $85.25 \pm 1.10 \%$ of $\mathrm{VO}_{2 \max }$ in NATL. AnT was reached at $87.57 \pm 1.30 \%$ of $\mathrm{VO}_{2 \max }$ in ATL and 84.64 \pm $1.10 \%$ of $\mathrm{VO}_{2 \max }$ in NATL. Hetlelid et al. [13] found AnT in well-trained and recreationally trained athletes to be at 90 and $83 \%$ of $\mathrm{VO}_{2 \max }$, respectively. Mickelson et al. [20] found $\mathrm{AnT}$ in elite athletes at $83 \% \mathrm{VO}_{2 \max }$. Our results coincide with previous studies confirming higher anaerobic capacities in athletes.

Pearson correlations for AnT and FAT $_{\text {min }}$ in ATL and NATL were very high $(r=0.99, p<0.01,95 \%$ CI 0.99 to 1.00 and $r=0.97, p<0.01,95 \%$ CI 0.91 to 0.98$)$, respectively. Large effect size explained $98.01 \%$ of variance in ATL demonstrating high strength of connection. The corresponding effect size in NATL explained $94.09 \%$ of variance.

Previous studies examining the variability of substrates utilization at high intensities did not report intensities and total fat and $\mathrm{CHO}$ oxidation values when $\mathrm{RQ} \geq 1$. Goedecke at al. [11] investigated substrate oxidation at three different intensities and reported RQ of 0.97 at last stage equaling $70 \%$ peak power output. Van Loon et al. [29] performed measurements at different intensities, with the last stage corresponding to $72 \% \mathrm{VO}_{2 \max }$. RQ was not reported, but it was stated that fat was contributing up to $25 \%$ to total energy production. Therefore, we estimated that last stage RQ was $0.92 \pm 0.05$. Stepto et al. [28] performed testing at $86 \% \mathrm{VO}_{2 \max }$ and reported $\mathrm{RQ}=0.92$. Coyle et al. [7] performed testing at $80 \% \mathrm{VO}_{2 \max }$ without reporting RQ but confirmed "high lactate threshold," leading to an assumption that exercise intensity was under AnT. Romijn et al. [25] performed testing at $85 \% \mathrm{VO}_{2 \max }$ and reported RQ of 0.91 . Hetlelid et al. [13] performed testing at 94 and $89 \%$ of $\mathrm{VO}_{2 \max }$ and reported RQ of 0.88 and 0.95 , respectively. The results of these studies suggest that, at the highest measured intensities, subjects were continuously under $\mathrm{RQ}=1$ or AnT, which may explain why fat oxidation was present.

To the best of our knowledge, there have been no studies on $\mathrm{CHO}$ utilization at intensities corresponding to AnT. In our study, ATL had CHO oxidation of $4.47 \pm 1.24 \mathrm{~g} \mathrm{~min}^{-1}$ when $\mathrm{RQ}=1.00$ contributing to $97.91 \pm 1.02 \%$ of total energy production. NATL had $4.17 \pm 0.95 \mathrm{~g} \mathrm{~min}^{-1} \mathrm{CHO}$ utilization $(\mathrm{RQ}=1.00)$ and $96.99 \pm 2.21 \%$ contribution to total energy expenditure. Rehrer et al. [24] found an average $\mathrm{CHO}$ oxidation to be $2.50 \mathrm{~g} \mathrm{~min}^{-1}$ at $70 \% \mathrm{VO}_{2 \max }$ in sedentary population, but did not report RQ. Stepto et al. [28] reported $\mathrm{CHO}$ oxidation of $4.95 \mathrm{~g} \mathrm{~min}^{-1}$ while cycling at $86 \% \mathrm{VO}_{2 \max }(\mathrm{RQ}=0.92)$ which is higher than in our study. Romijn et al. [25] reported $\mathrm{CHO}$ oxidation of $3.22 \mathrm{~g} \mathrm{~min}^{-1}$ in male cyclists at $85 \% \mathrm{VO}_{2 \max }$ and $\mathrm{RQ}=$ 0.91. Hetlelid et al. [13] reported $\mathrm{CHO}$ oxidation of $3.61 \mathrm{~g} \mathrm{~min}^{-1}(\mathrm{RQ}=0.88)$ at $94 \% \mathrm{VO}_{2 \max }$ and $3.79 \mathrm{~g} \mathrm{~min}^{-1}$ $(\mathrm{RQ}=0.95)$ at $89 \% \mathrm{VO}_{2 \max }$ in well-trained and recreationally trained athletes, respectively. Our data is in agreement with these studies; nevertheless, a direct comparison with other studies is difficult due to differences in factors affecting $\mathrm{CHO}$ utilization (diet, pre-training meal, age, sex, weather conditions, and testing methodology).

In our study, we used a GXT treadmill protocol with 2 -min stages and a constant incline of $1 \%$. With this type of protocol, we aimed to compensate for the lack of air resistance while running on a treadmill and to obtain more accurate and detailed sample data $[6,18]$. The average duration of the exercise stage was $16 \mathrm{~min}$ in ATL and 12 min in NATL. Numerous authors recommend that tests for $\mathrm{VO}_{2 \max }$ should last no longer as $12 \mathrm{~min}$, as prolonged tests could lead to inconsistent results [4, 23]. We noticed that athletes could not achieve $\mathrm{VO}_{2 \max }$ within 12 min due to their high endurance capacity, making short test stages more preferable. Finally, this type of protocol is highly correlative to running economy and actual $\mathrm{VO}_{2 \max }$ consumption with outdoor running. This provided additional reassurance that the protocol used is suitable for accurate measurement of $\mathrm{VO}_{2 \max }$, correlation assessment, and physiological testing of athletes in their natural environment $[6,18,22]$.

A mechanism behind lipid oxidation at high intensities has not been fully elucidated. With increased intensity, there is a gradual shift from fat as a primary fuel source to $\mathrm{CHO}$, until complete cessation of fat as a fuel for high-intensity exercise. This point, called FAT $_{\text {min }}$, highly correlates with AnT in our study. It is important to note two things: (1) AnT and $\mathrm{FAT}_{\text {min }}$ are interchangeable because they occur at the same individual point and (2) the point at which they occur depends on several factors such as training level and activity type, sex, age, and genetics which could explain both inter-subject and inter-study differences [16].

Additional benefits for athletes and coaches can be surmised from this study. The size of the glycogen storage depends on the muscle size, with approximately $500 \mathrm{~g}$ locally available (additional $100 \mathrm{~g}$ globally available in liver), corresponding to approximately $3000 \mathrm{kcal}$ of produced energy. Since there are no lipids available at intensities above AnT, CHO storage would be depleted after approximately $2 \mathrm{~h}$, contributing towards the effect known as "hitting the wall," therefore limiting not only athletes but also every subject performing at this level.

We consider as a key limitation of this study a rather small sample size which could affect our ability to estimate a causal relationship. Further studies with larger sample 
sizes including different types of subjects (sedentary, obese, different sports) would allow investigators to further understand how high-intensity exercise and the lipid oxidation are related. Other limitations include lack of control over the pre-test nutritional habits of the subjects which could have affected fat and $\mathrm{CHO}$ oxidation levels. High or low $\mathrm{CHO}$ diets could have some impact on total oxidation rates of the substrates making this question open for further studies.

\section{Conclusions}

In conclusion, this is the first study to report the point at which fat utilization ends at high-intensity exercise in male athletes and non-athletes. These results confirm our hypothesis that $\mathrm{FAT}_{\text {min }}$ and AnT are related and highly individual and therefore can be used as a determination end point of fat oxidation and to enhance exercise performance. Our data suggest no presence of lipids and demonstrated equal $\mathrm{CHO}$ oxidation levels at intensities matching AnT in both test groups.

\section{Acknowledgements}

The study authors would like to thank Pitre Bourdon and Scott Collier for technical and language editing support.

\section{Authors' Contributions}

$\mathrm{RP}$ contributed to the study design, data collection and analysis, and manuscript drafting. MM and ZN contributed to the study design and manuscript drafting. All authors read and approved the final manuscript

\section{Competing Interests}

Ratko Peric, Marco Meucci, and Zoran Nikolovski declare that they have no conflict of interest, and no financial support was received for the conduct of this study or preparation of this manuscript.

\section{Ethics Approval and Consent to Participate}

All procedures performed in studies involving human participants were in accordance with the ethical standards of the institutional and/or national research committee and with the 1964 Helsinki declaration and its later amendments or comparable ethical standards.

\section{Author details}

${ }^{1}$ Institute for Sport and Occupational Medicine Banja Luka, Zdrave Korde 4, 78000 Banja Luka, Bosnia and Herzegovina. ${ }^{2}$ Department of Health and Exercise Science, Appalachian State University, Boone, NC, USA. ${ }^{3}$ Department of Biochemistry, Aspire Academy, Doha, Qatar.

Received: 26 April 2016 Accepted: 22 August 2016

Published online: 31 August 2016

\section{References}

1. Achten J, Gleeson M, Jeukendrup AE. Determination of the exercise intensity that elicits maximal fat oxidation. Med Sci Sports Exer. 2002;34:92-7.

2. Achten J, Jeukendrup AE. Maximal fat oxidation during exercise in trained men. Int J Sports Med. 2003;24:603-8.

3. Astorino TA. Is the ventilatory threshold coincident with maximal fat oxidation during submaximal exercise in women? J Sports Med Phys Fitness. 2000;40(3): 209-16.

4. Bentley D, Newell J, Bishop D. Incremental exercise test design and analysis: implications for performance diagnostics in endurance athletes. Sports Med. 2007;37(7):575-86.

5. Bircher $\mathrm{S}$, Knechtle B. Relationship between fat oxidation and lactate threshold in athletes and obese women and men. J Sports Sci Med. 2004;3(3):174-81.
6. Billat VL, Hill DW, Pinoteau J, Petit B, Koralsztein JP. Effect of protocol on determination of velocity at $\mathrm{VO}_{2 \max }$ and on its time to exhaustion. Arch Physiol Biochem. 1996;104(3):313-21.

7. Coyle EF, Coggan AR, Hopper MK, Walters TJ. Determinants of endurance in well-trained cyclists. J Appl Physiol. 1988;64:2622-30.

8. Dyck DJ, Peters SA, Wendling PS, Chesley A, Hultman E, Spriet LL. Regulation of muscle glycogen phosphorylase activity during intense aerobic cycling with elevated FFA. Am J Physiol. 1996;270(1):116-25.

9. Dyck DJ, Putman CT, Hegenhauser GJF, Hultman E, Spriet LL. Regulation of fat-carbohydrate interaction in skeletal muscle during intense aerobic cycling. Am J Physiol. 1993;265(6):852-9.

10. Elia M, Livesey G. Energy expenditure and fuel selection in biological systems: the theory and practice of calculations based on indirect calorimetry and tracer methods. World Rev Nutr Diet. 1992;70:68-131.

11. Goedecke JH, St Clair GA, Grobler L, Collins M, Noakes TD, Lambert EV. Determinants of the variability in respiratory exchange ratio at rest and during exercise in trained athletes. Am J Physiol Endocrinol Metab. 2000; 279(6):1325-34.

12. Ghosh AK. Anaerobic threshold: its concept and role in endurance sport. Malays J Med Sci. 2004;11(1):24-36.

13. Hetlelid KJ, Plews DJ, Herold E, Laursen PB, Seiler S. Rethinking the role of fat oxidation: substrate utilization during high-intensity interval training in well-trained and recreationally trained runners. BMJ Open Sport Exerc Med. 2015:e000047. doi:10.1136/bmjsem-2015-000047.

14. Horowitz FJ, Klein S. Lipid metabolism during endurance exercise. Am J Clin Nutr. 2000:72(2):558-63.

15. Howley ET, Bassett DR, Welch HG. Criteria for maximal oxygen uptake: review and commentary. Med Sci Sports Exer. 1995;27(9):1292-301.

16. Jeukendrup AE. Modulation of carbohydrate and fat utilization by diet, exercise and environment. Biochem Soc Trans. 2003;31(6):1270-3. doi:10. 1042/bst0311270

17. Jeukendrup AE. Regulation of fat metabolism in skeletal muscle. Ann N Y Acad Sci. 2002:967:217-35.

18. Jones AM, Doust JH. A $1 \%$ treadmill grade most accurately reflects the energetic cost of outdoors running. J Sport Sci. 1996;14:321-7.

19 Maughan JR, Gleeson M. The biochemical basis of sports performance. $2^{\text {nd }}$ ed. Oxford University Press; 2010.

20 Mickelson TC, Hagerman FC. Anaerobic threshold measurements of elite oarsmen. Med Sci Sports Exer. 1982;14(6):440-4.

21 Meyer T, Lucia A, Earnest CO, Kindermann W. A conceptual framework for performance diagnosis and training prescription from submaximal gas exchange parameters —-theory and application. Int J Sports Med. 2005;26(1):38-48.

22 Mooses M, Tippi B, Mooses K, Durussel J, Mäestu J. Better economy in field running than on the treadmill: evidence from high-level distance runners. Biol Sport. 2015;32(2):155-9.

23 Pierce S, Hahn A, Davie A, Lawton E. Prolonged incremental tests do not necessarily compromise $\mathrm{VO}_{2 \max }$ in well-trained athletes. J Sci Med Sports. 1999;2(4):356-63.

24 Rehrer NJ, Wagenmakers AJM, Beckers EJ, Halliday D, Leiper JB, Brouns F, Maughan RJ, Westerterp K, Saris WHM. Gastric emptying, absorption and carbohydrate oxidation during prolonged exercise. J Appl Physiol. 1992; 72(2):468-75.

25 Romijn JA, Coyle EF, Sidossis LS, Zhang XJ, Wolfe RR. Regulation between fatty acid delivery and fatty acid oxidation during strenuous exercise. J Appl Physiol. 1995;79:1939-45.

26 Rapoport BI. Metabolic factors limiting performance in marathon runners. PLoS Comput Biol. 2010;6(10), e1000960. doi:10.1371/journal.pcbi.1000960.

27 Sidossis LS, Gastaldelli A, Klein S, Wolfe RR. Regulation of plasma fatty acid oxidation during low- and high-intensity exercise. Am J Physiol. 1997;272(6): 1065-70.

28 Stepto NK, Martin DT, Fallon KE, Hawley JA. Metabolic demands of intense aerobic interval training in competitive cyclists. Med Sci Sports Exer. 2001; 33:303-10.

29 Van Loon LC, Paul LG, Constantin TD, Saris WHM, Wagenmakers AJM. The effects of increasing exercise intensity on muscle fuel utilization in humans. J Physiol. 2001;536(1):295-304. 